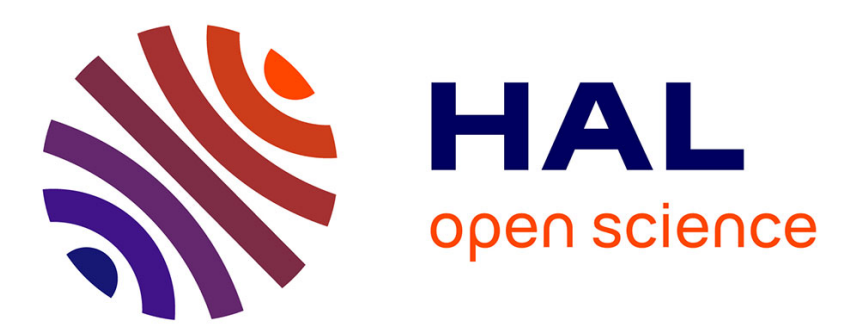

\title{
Structural and Morphological Changes In Ag:TiN Nanocomposite Films promoted by in-vacuum annealing
}

Diogo Machado, Paulo Pedrosa, Carlos Fonseca, Nicolas Martin, Filipe Vaz

\section{To cite this version:}

Diogo Machado, Paulo Pedrosa, Carlos Fonseca, Nicolas Martin, Filipe Vaz. Structural and Morphological Changes In Ag:TiN Nanocomposite Films promoted by in-vacuum annealing. Journal of Nano Research, 2013, 25, pp.67 - 76. 10.4028/www.scientific.net/JNanoR.25.67 . hal-00877323

\section{HAL Id: hal-00877323 https://hal.science/hal-00877323}

Submitted on 28 Oct 2013

HAL is a multi-disciplinary open access archive for the deposit and dissemination of scientific research documents, whether they are published or not. The documents may come from teaching and research institutions in France or abroad, or from public or private research centers.
L'archive ouverte pluridisciplinaire HAL, est destinée au dépôt et à la diffusion de documents scientifiques de niveau recherche, publiés ou non, émanant des établissements d'enseignement et de recherche français ou étrangers, des laboratoires publics ou privés. 


\title{
STRUCTURAL AND MORPHOLOGICAL CHANGES IN Ag:TiN NANOCOMPOSITE FILMS PROMOTED BY IN-VACUUM ANNEALING
}

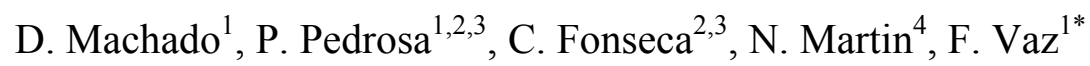

\begin{abstract}
${ }^{1}$ Centro de Física, Universidade do Minho, 4710-057 Braga, Portugal
${ }^{2}$ Universidade do Porto, Faculdade de Engenharia, Departamento de Engenharia Metalúrgica e de Materiais, Rua Roberto Frias, s/n, 4200-465 Porto, Portugal ${ }^{3}$ SEG-CEMUC - Department Mechanical Engineering, University of Coimbra, Portugal ${ }^{4}$ Institut FEMTO-ST, UMR 6174, Université de Franche-Comté, CNRS, ENSMM, UTBM, 32, Avenue de l'observatoire, 25044 BESANCON Cedex, France
\end{abstract}

\begin{abstract}
Thin films composed of titanium nitride doped with silver were deposited by DC reactive sputtering, with Ag contents varying between 0 and 50 at.\%. The as-deposited samples were subjected to vacuum annealing treatments, with a range of temperatures varying from 200 to $500^{\circ} \mathrm{C}$, in order to study the morphological and structural changes that may occur. The as-deposited samples showed three main zones of basic characteristics, which differ both in terms of the morphology and structural features. With the increase of the annealing temperature, the thermodynamic stability was accelerated, revealing a phenomenon of dispersion of silver particles at $200{ }^{\circ} \mathrm{C}$ and the start of its segregation at $300{ }^{\circ} \mathrm{C}$. At $400{ }^{\circ} \mathrm{C}$, the coalescence of the segregated $\mathrm{Ag}$ particles begins, while at $500{ }^{\circ} \mathrm{C}$ the formation of large clusters of $\mathrm{Ag}$ is glaring, particularly in the samples with higher Ag content. In addition, and corroborating the
\end{abstract}

*To whom all correspondence should be sent (fvaz@fisica.uminho.pt) 
presence of free $\mathrm{Ag}$ in the thin films, the increase of the annealing temperature promotes coating's crystallinity and some Ag grain growth.

Keywords: Titanium nitride; silver; vacuum annealing; morphology; structure;

\section{INTRODUCTION}

The past five decades have seen an increasingly important development in the area of bio-electrodes that are used to measure bioelectric signals, produced by organs of the human body. Electrocardiography (ECG), electroencephalography (EEG) and electromyography (EMG) are some examples of such electrode applications $[1,2]$. Coated materials are among the most recent attempts to increase the capabilities of these bio-electrodes, with a clear focus on the improvement of signal quality and accuracy of the devices. Several elemental or even multiple component composites have been tried in recent years by several research groups, differing mostly in their adequacy to the final outputs that are to be measured and characterized [3-11]. More recently, different types of nanocomposite thin films have been studied because their combined structures, which comprises two or more components having diverse properties, making it possible to achieve better performance and functionality than those of single components [12-14].

Among the most investigated material types, sputtered TiN is a well-known thin film material, widely used in electrical- and tribological-based applications, due to its good electrical conductivity and corrosion/oxidation resistance [3], heat resistance, high chemical stability, wear resistance [4], scratch resistance [5] and high hardness ( $\sim 20$ GPa) [6], specially at moderated temperatures [7]. Due to its good biocompatibility, it has also been used in the biomedical research area [8]. Nevertheless, TiN has some disadvantages regarding the absence of antibacterial ability [9], which limits its use in 
some important biomedical applications. Anyway, this drawback can be compensated by the addition of some well-known antibacterial materials, where Ag is one of the most used [10]. In addition, Ag also allows obtaining the so-called 'self-lubricating' effect [7], together with the possibility to tailor the final composite mechanical performance, namely its elasticity. This last possibility is extremely important in modern flexible-like devices, such as polymeric-based electrodes. This set of characteristics is essential when it comes to applications like tribological-based ones, which derives from the lubricating skill of silver solid particles merged in a TiN matrix, changing its recognized high friction coefficient and hereafter making it suitable for tribological solicitations [7]. Furthermore, Ag has one of the lowest resistivity values among all metals (below $2 \times 10^{-8} \Omega . \mathrm{m}$ at room temperature). Moreover, $\mathrm{Ag}$ has low mechanical strength, which is why it has been used in integrated circuit interconnects, electrodes and optical mirrors [11].

In spite of the promising effects that may arise from the joining of both $\mathrm{TiN}$ and $\mathrm{Ag}$ systems in a single material, which would allow to tailor the final composite material with both systems' characteristics, the composite Ag:TiN system may have some important drawbacks. These concern the structural and morphological stability, namely the growth characteristics and crystalline structure evolution, as well as the Ag diffusion throughout the film thickness itself $[7,15-16]$. There are well-known problems related to mechanical failures in the coatings, particularly due to changes in their morphology or crystalline phases, which in turn significantly aggravate the efficiency/performance of the thin films during their in-service performance $[15,16]$. These problems reveal a major importance in situations that involve high operating temperatures, such as those resulting from friction in tribological applications, making the study of the thermal (morphological and structural related behaviours) stability of crucial importance [17]. 
Taking this as a start point, the present paper discusses the influence of different annealing temperatures on the structural and morphological stability of Ag:TiN thin films, in order to better understand the major changes that are promoted, namely in what concerns a rather well-known characteristic of silver-based nanocomposites, such as its significant diffusion throughout the entire film thickness, as well as the related coalescence processes [18].

\section{EXPERIMENTAL DETAILS}

Glass and (100) silicon substrates were used to deposit Ag:TiN thin films using the reactive DC magnetron sputtering technique in a laboratory-sized deposition system. Before each deposition, all substrates were subject to a cleaning process with ethanol $96 \%$ (vol.) in order to avoid possible contamination. Inside the deposition chamber, the substrate holder was positioned at a distance of about $70 \mathrm{~mm}$ from the $\mathrm{Ti} / \mathrm{Ag}$ composite target. The target was composed of titanium (99.96 at.\% with $\left.2 \times 1 \times 0.06 \mathrm{~cm}^{3}\right)$ and silver pellets (with a dimension of $8 \times 8 \times 1\left(\times 10^{-2}\right) \mathrm{cm}^{3}$ and a total surface area that varied between 0.75 and $8.3 \mathrm{~cm}^{2}$ ) glued symmetrically along the erosion area on the surface of the target. A DC current density of 100 A.m ${ }^{-2}$ was used and the base pressure was always in the $10^{-4} \mathrm{~Pa}$ range. Regarding the deposition conditions, a gas atmosphere composed of argon (with a constant flow rate of $60 \mathrm{sccm}$ for all depositions corresponding to a partial pressure of $3 \times 10^{-1} \mathrm{~Pa}$ ) and nitrogen (with a flow rate of 5 sccm; partial pressure of $3.4 \times 10^{-2} \mathrm{~Pa}$ ) was used. The working pressure was approximately constant during the depositions, varying only slightly between 0.35 and $0.38 \mathrm{~Pa}$. No bias voltage was used, and the deposition temperature was controlled by a thermocouple placed at approximately $7 \mathrm{~cm}$ to the surface of the substrate holder (not in direct contact, once the depositions were carried out in rotation mode). The temperature 
was kept constant at $100{ }^{\circ} \mathrm{C}$ during the $3600 \mathrm{~s}$ of deposition time. Before each deposition, the Ti/Ag target was subjected to a 300 s pre-sputtering, with the purpose of avoiding film contamination resulting from previous depositions (which may have resulted in some target poisoning). The as-deposited samples were then subjected to an annealing treatment in a vacuum furnace at a pressure of approximately of $10^{-4} \mathrm{~Pa}$. The annealing temperatures ranged between 200 and $500{ }^{\circ} \mathrm{C}$ (the upper limit is known as the limit temperature until which TiN coatings may be used). The annealing process consists in three main steps: firstly a heating stage of $5^{\circ} \mathrm{C} / \mathrm{min}$, followed by a $60 \mathrm{~min}$. stabilization step. Finally, before removing the samples, they were cooled down freely to room temperature still in vacuum conditions. The atomic composition of the asdeposited samples was measured by Rutherford Backscattering Spectroscopy (RBS) using $(1.4,2.3) \mathrm{MeV}$ and $(1.4,2) \mathrm{MeV}$ for the proton and ${ }^{4} \mathrm{He}$ beams, respectively. Three detectors were used; one located at a scattering angle of $140^{\circ}$ and two pin-diode detectors located symmetrical to each other, both at $165^{\circ}$. Measurements were made for two sample tilt angles, $0^{\circ}$ and $30^{\circ}$. Composition profiles for the as-deposited samples were determined using the software NDF [19]. The area analysed was about $0.5 \times 0.5$ $\mathrm{mm}^{2}$. The uncertainty in the $\mathrm{N}$ concentrations is around 5 at.\%. The structure and phase distribution of the coatings were assessed by X-ray diffraction (XRD), using a Bruker AXS Discover D8 diffractometer, operating with $\mathrm{Cu} \mathrm{K}_{\alpha}$ radiation and in a BraggBrentano configuration. The XRD patterns were deconvoluted and fitted with a Voigt function to determine the structural characteristics of the films, such as the peak position (29), the full width at half maximum (FWHM) and the crystallite size. Morphological features of the samples were probed by scanning electron microscopy (SEM), carried out in a FEI Nova 200 (FEG/SEM) microscope operating at $15 \mathrm{keV}$. 


\section{RESULTS AND DISCUSSION}

\subsection{Preparation of a set of representative samples}

In a previous study, the authors co-deposited Ag:TiN nanocomposites, and related the thin film characteristics with the selected deposition conditions [20]. Three different zones were identified, directly related to their set of properties that were correlated with the main changes in structural and morphological features [20]. Taking this into account, five representative samples of the three identified zones were then selected, according to their different $\mathrm{Ag}$ contents, and the correspondent morphological and structural changes. The sample with a Ag content of 0.1 at.\% represents a group of samples with a very low amount of metal nanoparticles, revealing an overall behaviour that can be identified as quite similar to that of TiN. This set of low Ag content samples was indexed to a first zone of samples, zone I. A second group of samples was then identified, consisting of intermediate Ag content films, where some important changes have occurred in comparison to the TiN-like one from zone I films. The samples with Ag contents of 6.3 at.\% and 20.2 at.\% Ag represent this group of samples (zone II). Finally, a third group of thin films was prepared, where the silver content was relatively high, ranging from $\sim 35$ at. $\%$ to $\sim 47.5$ at. $\%$, with a clear tendency for the films to reveal a behaviour approaching that of pure Ag films. Two samples, containing amounts of $\mathrm{Ag}$ of 36.3 at.\% and 47.5 at.\% $\mathrm{Ag}$ are representative of this third identified group (zone III).

Regarding the main characteristics of each zone of films, the samples from zone I (very low Ag incorporation) revealed a TiN-like character, where the lower values of the deposition rate (around $1.3 \mu \mathrm{m} / \mathrm{h}$ ), Fig. 1, are in good agreement with the available values for pure TiN deposition conditions $(\sim 1.2 \mu \mathrm{m} / \mathrm{h}$ [5]), Fig. 2 . For the films indexed to zone II, it is notorious a change in the deposition rate evolution, which seems to level off, Fig. 1. However, the exhibited values are slightly lower in relation to zone I, due to 
an increase of $\mathrm{Ag}$ incorporation, consequence of the increasing $\mathrm{Ag}$ fraction in the $\mathrm{Ti} / \mathrm{Ag}$ target erosion zone (between 1 and $5 \mathrm{~cm}^{2}$ ) [20], Fig. 2 .

It is important to notice an initial low level of $\mathrm{Ag}$ composition in the films, followed by a steep increase of the $\mathrm{Ag} /(\mathrm{Ti}+\mathrm{N})$ ratio connected to the $\mathrm{Ag}$ concentration (from 6.3 to $\sim 36.3$ at.\%). Finally, the samples from zone III display increasing deposition rate values, Fig. 1, due to a strong increase of the $\mathrm{Ag}$ exposed area $\left(\geq 5 \mathrm{~cm}^{2}\right)$. The less accentuated increase in Ag content for concentrations ranging from $~ 36.3$ to $\sim 47.5$ at. $\%$ is probably due to Ag saturation in the TiN matrix.

\subsection{Morphological and structural characterization}

Taking into account the five representative samples mentioned before, and in order to study the coatings' structural and morphological stability, a set of in-vacuum annealing tests were carried out. The morphological evolution in the coatings as a function of the annealing temperature, carried out by SEM investigation, showed two main morphological changes, within the annealing temperature range (from $200{ }^{\circ} \mathrm{C}$ to $500{ }^{\circ} \mathrm{C}$ ). The first one is linked with the coating growth-type (including aspects as densification and porosity), while the second is associated to a systematic grain growth and formation of extensive Ag nanoparticles (aggregates). Anyway, it is worth noticing that one could identify very similar changes in all five representative samples, although with much clearer evidence in the samples with the highest silver contents (zone III). Following this clearer morphological changes, Fig. 3 shows SEM cross-section images $\left(\mathrm{A}_{1-4}\right)$ and top view $\left(\mathrm{B}_{1-4}\right)$ micrographs of the Ag:TiN sample with a Ag content of 36.3 at.\%, uncovering the most important changes that occurred in the film's morphological features. At $200{ }^{\circ} \mathrm{C}$ (Fig. $3 \mathrm{~A}_{1}$ ), the sample shows a typical TiN-like columnar growth, with some disaggregation areas, characterized by an increase of the thin film porosity 
and the presence of some small Ag particles $(<1 \mu \mathrm{m})$, both on the surface (in smaller quantities) and throughout the film thickness, demonstrating some homogeneous distribution. At $300{ }^{\circ} \mathrm{C}$ (Fig. $3 \mathrm{~A}_{2}$ ), there are now major changes in morphological terms, jumping into sight the formation of $\mathrm{Ag}$ diffusion lines (small $\mathrm{Ag}$ particles forming some kind of diffusion path) along the columnar boundaries, as if illustrating the way that these same particles travelled while diffusing to the surface. It is also possible to observe the formation of some rather large Ag clusters on the surface. At $400{ }^{\circ} \mathrm{C}$ (Fig. $3 \mathrm{~A}_{3}$ ), there is a slight decrease in the number of $\mathrm{Ag}$ aggregates, associated with an increase of the spherical definition of the Ag particles shape (becoming nearly spherical) [21][6], together with a slight increase in the aggregate's dimension on the surface $[22,23]$. Confirming this fact, it is visible at $500{ }^{\circ} \mathrm{C}$ (Fig. $3 \mathrm{~A}_{4}$ ) a radical dimensional increase of the Ag clusters sitting in the sample's surface (similar to the coating thickness: $>1 \mu \mathrm{m})$, losing their spherical shape. This phenomenon may have resulted from an almost complete segregation of all the small particles embedded along the boundaries of the columnar coating to the surface, having probably reached the percolation threshold. This phenomenon of silver diffusion has been observed also by Kitawaki et al. [6], which verified the existence of free metallic silver, justifying that the silver atoms are not bonded to the TiN matrix (forming a kind of Ti-N-Ag intermetallic), since the nitrification of silver is thermodynamically unlikely due to its high enthalpy of formation when compared to $\operatorname{TiN}\left(\Delta_{\mathrm{f}} \mathrm{H}_{\varnothing}=309 \mathrm{~kJ} \mathrm{~mol}^{-1}\right.$ to $\mathrm{AgN}_{3}, 199$ $\mathrm{kJ} \mathrm{mol}^{-1}$ for $\mathrm{Ag}_{3} \mathrm{~N}$, and $-338.1 \mathrm{~kJ} \mathrm{~mol}^{-1}$ for TiN). Also, Kelly et al. [10] observed this phenomenon of Ag segregation, where the silver nanoparticles were observed uniformly distributed along the surface of the TiN matrix. Similarly, Moreno et al. [24] reported the same silver diffusion phenomenon to the surface for the case of a $\mathrm{Cu}$ matrix, stating that the $\mathrm{Cu}-\mathrm{Ag}$ alloys tend to form a double phase due to the high enthalpy of formation. 
The segregation of silver was also confirmed by Gulbiński and Suszko [25], that studied this phenomenon in another metal nitride $(\mathrm{MoN})$, indicating that higher amounts of silver segregation in grain boundaries prevent the growth of the MoN structure, gradually decreasing its crystallinity. In the same framework, a study conducted by Resnik et al. [26] demonstrated that the temperature increase causes a faster approximation of the thermodynamic equilibrium, thereby increasing the diffusion of metals such as silver to the surface of the base matrix.

Aiming at better understanding how the morphological changes affect, first, the films structural arrangements, and then the overall films' behaviour, a detailed structural characterization was carried out, both in the as-deposited and annealed samples. Again, similar trends were observed in all five representative samples, though their extension was somehow different for the diverse Ag contents. Figure 4 shows the XRD diffractograms of the Ag:TiN samples with a Ag content of 0.1 at.\% (zone I), 20.2 at.\% (zone II) and 36.3 at.\% (zone III), at room temperature and at the different annealing temperatures. Figure 4.a) shows the behaviour of the sample with a Ag content of 0.1 at. $\%$, where, as expected (due to the very low Ag content) and both at room temperature and with increasing annealing temperature, only TiN peaks are observed, corresponding to a fcc TiN-type structure (ICDD card 00-038-1420), typical for stoichiometric TiN thin films [27]. There are no Ag peaks, which is somewhat expected, again due to the low Ag content in the sample. With increasing annealing temperature, it seems that an increasing definition/intensity of all diffraction peaks is present, which can be associated to an increase of the thin film's crystallinity. A closer look to the diffraction peaks reveals that a small shift in the angular position to higher diffraction angles. This implies a decrease in the lattice parameter, which can be explained by the contraction of the TiN structure, resulting from a possible migration of a few $\mathrm{Ag}$ atoms (that 
precipitated at the grain boundaries [2]), which then segregated to the thin film's surface.

Regarding the structural evolution with the set of films indexed to zone II [20], Fig. 4.b) show the diffractograms of the as-deposited and annealed sample with a Ag content of 20.2 at.\%. This figure shows the presence of two main peaks: one corresponding to the (111) peak of fcc-TiN, located at $2 \theta \sim 36^{\circ}$, and the other to the diffraction of a fcc Ag-type structure ((111) reflection), located at an angular position of $2 \theta \sim 38^{\circ}$ (ICDD card 00-004-0783). This is a typical behaviour for $\mathrm{Ag}$ thin films [25, 26, 28]. Furthermore, a closer look at the diffractograms corresponding to annealing temperatures of 200 and $300{ }^{\circ} \mathrm{C}$, seems to evidence that a decreasing definition/intensity of TiN diffraction peaks is occurring, which is in opposition to what happens in the diffraction results corresponding to the Ag phase. From 400 to $500{ }^{\circ} \mathrm{C}$, all diffraction peaks increase their definition/intensity, possibly due to an increase of the thin film's crystallinity with increasing temperature (grain refinement and crystal growth, as seen in SEM observations). The same shift of the diffraction peaks to higher angular positions was observed in these annealing temperatures, becoming even clearer, possibly due to the higher amount of Ag that is diffusing to the surface. Figure 4.c) illustrates the behaviour of the set of films that were indexed to zone III, where it is noteworthy the appearance of a diffraction peak at an angular position of $2 \theta \sim 44^{\circ}$ (corresponding to the (200) peaks of a Ag fcc-type structure), with an increased definition, possibly indicating the beginning of the $\mathrm{Ag}$ segregation and its clustering. It is also worth noting the appearance of a new peak at a diffraction angle of $2 \theta \sim 64^{\circ}$, corresponding to the Ag fcc-type structure ((220) diffraction planes). Contrary to this increasing crystallinity of the Ag phase, TiN becomes increasingly amorphous with increasing temperature, probably due to the hindered growth promoted by the solute- 
drag effect [29]. From 400 up to $500{ }^{\circ} \mathrm{C}$ there is clearly an approximation in terms of definition and intensity among $\mathrm{Ag}$ and TiN diffraction peaks, consistent with the formation of large Ag clusters, as corroborated by the SEM micrographs. It is also worth to highlight the formation of a new peak at approximately $2 \theta \sim 78^{\circ}$, which can be indexed to the diffraction of fcc-Ag crystal structure ((311) planes).

A deeper analysis of the structural and morphological features was obtained by the study of the influence of the annealing temperature in the evolution of the grain size of both Ag and TiN crystalline phases. The results of XRD signals fitting of both (111) peak from the fcc-TiN phase and (111) peak from the Ag phase are shown in Fig. 5. This peak fitting allowed further uncovering of the main structural and morphological changes previously enounced. In fact, the results plotted in Fig. 5 reveal that with increasing temperature, two different behaviour zones of $\mathrm{Ag}$ and TiN grain sizes are developed. Firstly, the zone where it can be observed grain size values varying from 17 to $19 \mathrm{~nm}$ for $\mathrm{TiN}$ (111) and from 13 to $15 \mathrm{~nm}$ for $\mathrm{Ag}$ (111). This zone can be characterized by the temperature range that is insufficient to promote Ag segregation, thus exhibiting higher values of TiN grain size comparatively to Ag. Above $300{ }^{\circ} \mathrm{C}$, it is notorious a different zone, where an increasing annealing temperature leads to a slight increase of the TiN grain size (although the values are still below the ones from the first zone) and a steep increase of the Ag grain size, once the free metallic silver atoms embedded in the TiN matrix easily segregate and coalesce (increasing Ag grain size) by action of the high temperatures. Indeed, the Ag incorporation causes a decrease in the TiN matrix grain size as the segregation of the Ag grains occurs preferentially across the TiN grain boundaries, thus hindering the TiN grain size growth [2]. This growth of $\mathrm{Ag}$ particles was already observed by SEM micrographs. 
In an overview mode, the authors would like to suggest a schematic model that may represent the entire evolution of the microstructural features of the thin films with the annealing temperature and with the change of the Ag content. This model is illustrated by Fig. 6, involving the three mentioned behaviour zones, which with increasing annealing temperature, evolve likewise. As the annealing temperature was increased, one could identify four different distinct events. First, and occurring at room temperature, a TiN-like behaviour can be claimed, where the coatings show a columnarlike structure. This behaviour was identified to be present within all the films that were prepared with very low amounts of metallic nanoparticles - the low Ag content zone (zone I). With the increase of the Ag content, a progressive destruction of the columnar structures could be identified, resulting from the incorporation of the Ag particles. At $200{ }^{\circ} \mathrm{C}$, the dispersion of the Ag nanoparticles was observed, with/or even an atomic reorganization, distributed through the entire samples' thickness. Increasing the annealing temperature further to $300^{\circ} \mathrm{C}$, it is clearly the beginning of the segregation phenomenon, that occurred as a result of the reorganization of the Ag particles in the form of "lines" of segregation between the columnar structures (samples from zone II) and within an almost featureless zone (zone III), where the columnar structure seems not to be present. When the annealing temperature reaches 400 and $500{ }^{\circ} \mathrm{C}$, two different phenomena are interconnected. At $400{ }^{\circ} \mathrm{C}$, the $\mathrm{Ag}$ particles, which had been previously segregated, coalesce at the surface, forming bigger particles along the entire sample. Finally, at $500{ }^{\circ} \mathrm{C}$, these "giant" particles agglutinate at the surface, revealing Ag islands with sizes close to that of the film thickness itself. A summary of these observations is depicted in Fig. 6.

\section{CONCLUSIONS}


In this paper it is conceivable to associate the influence of several annealing temperatures carried out on Ag:TiN coatings produced by magnetron sputtering, in their morphological and structural behaviours. Regarding the deposition rate, it was detected the existence of three different zones of behaviour: (i) a first zone (zone I) with deposition rate values that are similar to the ones exhibited by pure TiN, thus this zone can be considered a TiN-like zone, (ii) a second zone (zone II) which shows lower (and constant) values than in the first zone and (iii) a third zone (zone III) that shows an increase of the deposition rate and a growing $\mathrm{Ag}$ incorporation with the increase of $\mathrm{Ag}$ exposed area in the $\mathrm{Ti} / \mathrm{Ag}$ target. Concerning the morphological progress with increasing annealing temperatures, it was possible to identify the existence of a significant Ag segregation phenomenon, initially in the form of spherical particles located both among the TiN columns, as well as at the thin film's surface. The Ag particles embedded in the TiN matrix later spread to the surface where they agglutinate to form agglomerates of dimensions similar to those of the coating thickness by action of increasing annealing temperatures. The applied thermal treatments, beyond proving the presence of free metallic silver atoms, also resulted in some structural modifications on the studied sample, providing increasing crystallinity to the coating (higher peak definition).

To sum up the several heat treatments effect on the Ag:TiN samples, their behaviour can be consistently ascribed to three distinct zones (zone I, zone II and zone III), both at the structural and morphological levels, as expected. In fact, the increase of the annealing temperature increases the mobility of the coating's species, therefore significantly affecting its structure and morphology, confirming the observed results.

\section{ACKNOWLEDGEMENTS}


This research is partially sponsored by FEDER funds through the program COMPETE - Programa Operacional Factores de Competitividade and by national funds through FCT - Fundação para a Ciência e a Tecnologia, under the projects PEstC/EME/UI0285/2011, $\quad$ PTDC/SAU-ENB/116850/2010, PTDC/CTMNAN/112574/2009 and Programa Pessoa 2012/2013 Cooperação Portugal/França, Project $\mathrm{n}^{\mathrm{o}}$ 27306UA. P. Pedrosa acknowledges FCT for the Ph.D. grant SFRH/BD/70035/2010. 


\section{REFERENCES}

[1] C. O’Mahony, F. Pini, A. Blake, C. Webster, J. O’Brien, K. G. McCarthy, C. O. Mahony, J. O. Brien, Sensors and Actuators A: Physical, 186 (2012) 130-136 2012.

[2] M. Teplan, M. S. Review, Measurement Science Review, 2 (2002) 1-11.

[3] S. Rtimi, O. Baghriche, R. Sanjines, C. Pulgarin, M. Ben-Simon, J.-C. Lavanchy, A. Houas, J. Kiwi, Appl. Catalysis B: Environmental, 123-124 (2012) 306-315.

[4] J. Zhao, X.M. Cai, H. Q. Tang, T. Liu, H.Q. Gu, R.Z. Cui, Journal of materials science. Materials in medicine, 20 (1) (2009) S101-5.

[5] K. Lal, A.K. Meikap, S.K. Chattopadhyay, S.K. Chatterjee, M. Ghosh, K. Baba, R. Hatada, Physica B: Condensed Matter, 307 (1-4) (2001) 150-157.

[6] K. Kitawaki, K. Kaneko, K. Inoke, J.C. Hernandez-Garrido, P. Midgley, H. Okuyama, M. Uda, Y. Sakka, Micron, 40 (3) (2009) 308-12.

[7] H.Ko, H. Köstenbauer, G.A. Fontalvo, C. Mitterer, J. Keckes, Tribology Letters, 30 (1) (2011) 53-60.

[8] P.J. Kelly, H. Li, K. Whitehead, J. Verran, R. D. Arnell, I. Iordanova, Sur. Coat. Technol., 204 (6-7) (2009) 1137-1140.

[9] J. Zhao, H.J. Feng, H.Q. Tang, J.H. Zheng, Sur. Coat. Technol., 201 (9-11) (2007) 5676-5679.

[10] P.J. Kelly, H.Li, P. S. Benson, K.A. Whitehead, J. Verran, R.D. Arnell, I. Iordanova, Surf. Coat. Technol., 205 (5) (2010) 1606-1610.

[11] N. Artunç, M.D. Bilge, G. Utlu, Surface and Coatings Technology, 201 (19-20) (2007) 8377-8381.

[12] M. Zhang, L. Hu, G. Lin, Z. Shao, Journal of Power Sources, 198 (2012) 196202.

[13] J. Musil, J. Vlcek, Surf. Coat. Technol., 557 (2001) 142-144.

[14] Y.Y. Tse, D. Babonneau, A. Michel, G. Abadias, Surface and Coatings Technology, 180-181 (2004) 470-477.

[15] M. Torrell, R. Kabir, L. Cunha, M.I. Vasilevskiy, F. Vaz, A. Cavaleiro, E. Alves, N. P. Barradas, J. Appl. Phys., 109 (2011) 074310-074319. 
[16] F. Vaz, R.C. Adochite, M. Torrell, L. Cunha, E. Alves, N.P. Barradas, A. Cavaleiro, J.P. Rivière, D. Eyidi, Optoelectron. Adv. Mater.-Rapid Commun., 5 (1-2) (2011) 73-79.

[17] N.J. Simrick, J.A. Kilner, A. Atkinson, Thin Solid Films, 520 (7) (2012) 28552867.

[18] L. Gao, J. Gstöttner, R. Emling, M. Balden, C. Linsmeier, A. Wiltner, W. Hansch, D. Schmitt-Landsiedel, Microelectronic Engineering, 76 (1-4) (2004) $76-81$.

[19] N.P. Barradas, C. Jeynes, R. P. Webb, Appl. Phys. Lett., 71 (1997) 291.

[20] P. Pedrosa, C. Lopes, D. Machado, E. Alves, N.P. Barradas, N. Martin, F. Macedo, C. Fonseca, F. Vaz, Submitted to Applied Surface Science.

[21] B. Yang, R.-R. Ma, D.-M. Li, A.-G. Xia, X.-M. Tao, Thin Solid Films, 520 (6) (2012) 2321-2325.

[22] O. Akhavan, A. Z. Moshfegh, Appl. Sur. Sci., 254 (2) (2007) 548-551.

[23] M.M. Viana, N.D.S. Mohallem, D.R. Miquita, K. Balzuweit, E. Silva-Pinto, Appl. Surf. Sci., 265 (2013) 130-136.

[24] V. Moreno, J. Creuze, F. Berthier, C. Mottet, G. Tréglia, B. Legrand, Surf. Sci., 600 (22) (2006) 5011-5020.

[25] W. Gulbiński, T. Suszko, Surf. Coat. Technol., 201 (3-4) (2006) 1469-1476.

[26] D. Resnik, J. Kovač, D. Vrtačnik, S. Amon, Thin Solid Films, 516 (21) (2008) 7497-7504.

[27] J. C. Sánchez-López, M. D. Abad, I. Carvalho, R. Escobar Galindo, N. Benito, S. Ribeiro, M. Henriques, A. Cavaleiro, S. Carvalho, Surf. Coat. Technol., 206 (89) (2012) 2192-2198.

[28] H. Köstenbauer, G. A. Fontalvo, J. Keckes, C. Mitterer, Thin Solid Films, 516 (8) (2008) 1920-1924.

[29] Z.-J. Liu., Y. G. Shen, Journal of Vacuum Science \& Technology A, 24 (1) (2006) 174-178. 


\section{Figure captions}

Fig. 1. Evolution of the deposition rate with increasing Ag exposed area in the target.

Fig. 2. Evolution of the coatings' $\mathrm{Ag}$ content and $\mathrm{Ag} /(\mathrm{Ti}+\mathrm{N})$ ratio as a function of the $\mathrm{Ag}$ exposed area in the target.

Fig. 3. SEM cross-section $\left(a_{1-4}\right)$ and top view $\left(b_{1-4}\right)$ of the sample with a Ag content of 36.3 at. $\%$ with increasing annealing temperature.

Fig. 4. XRD diffractograms of one of the representative samples from each zone ((a) zone I - sample with a Ag content of 0.1 at.\%; (b) zone II - sample with a Ag content of 36.3 at.\%; (c) zone III - sample with a $\mathrm{Ag}$ content of 36.3 at.\% with increasing annealing temperature.

Fig. 5. Influence of the annealing temperature on the grain size evolution of TiN (111) and $\mathrm{Ag}(111)$ peaks of the five representative samples.

Fig. 6. General model depicting the overall influence of the annealing treatments and the Ag content on the microstructural evolution of the samples. 
Figure 1

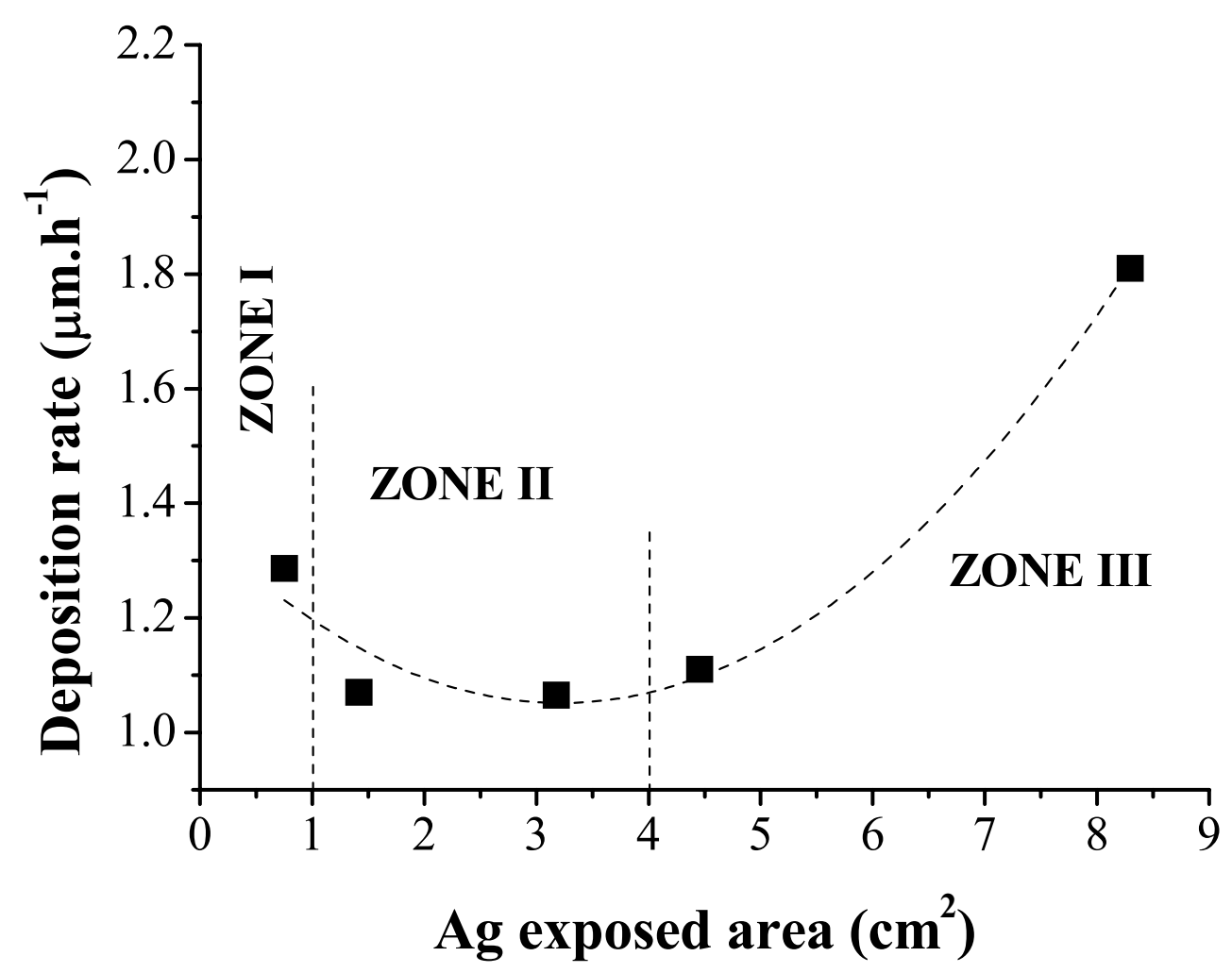


Figure 2

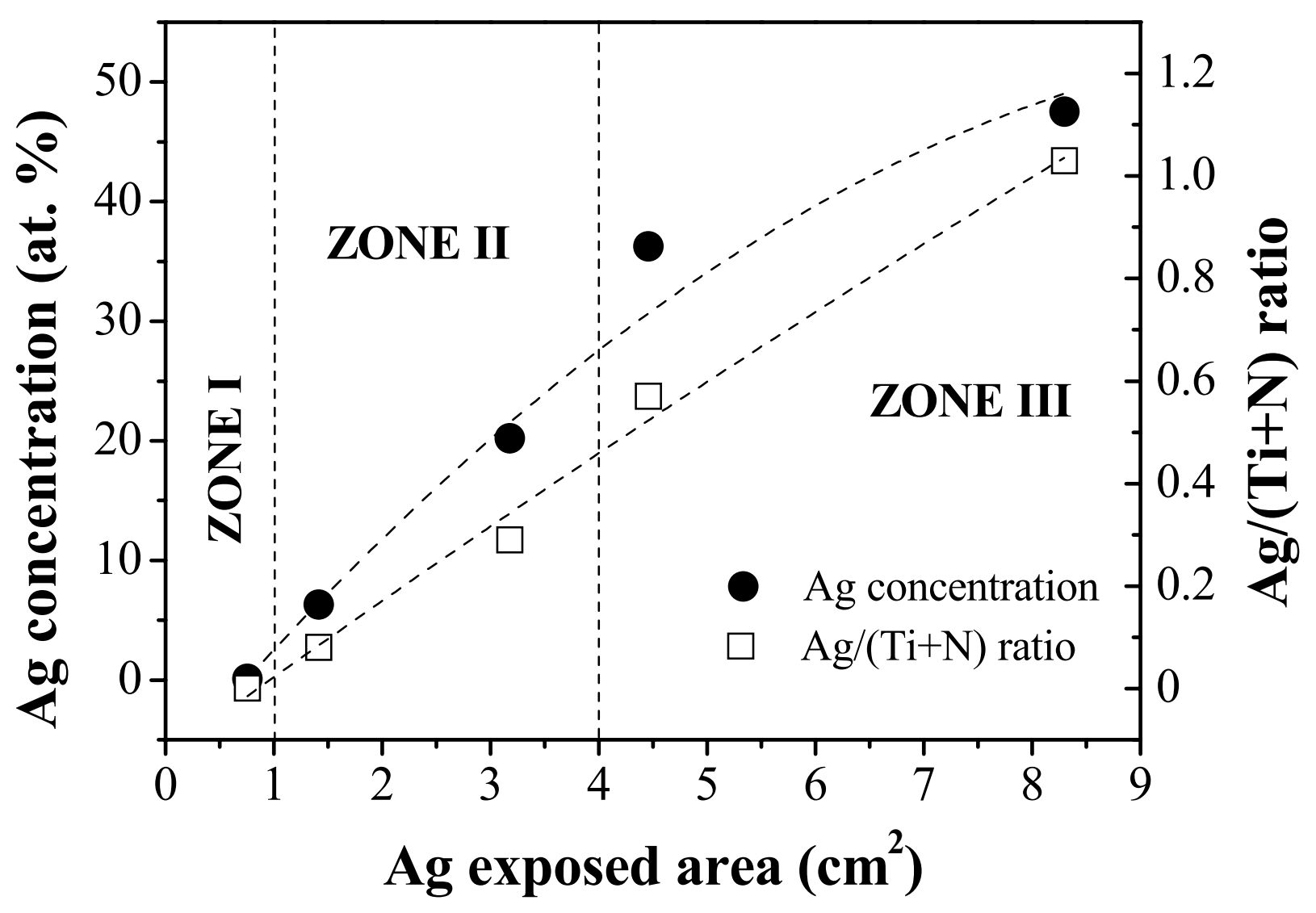


Figure 3

$200^{\circ} \mathrm{C}$
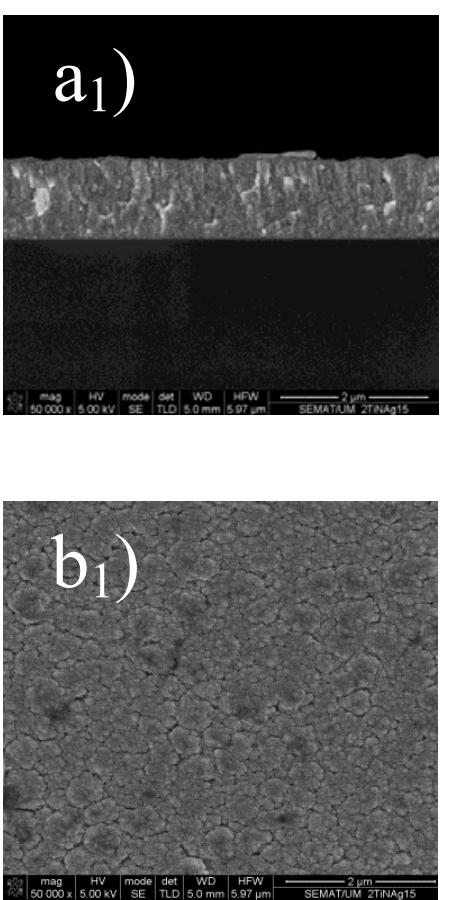

$300^{\circ} \mathrm{C}$
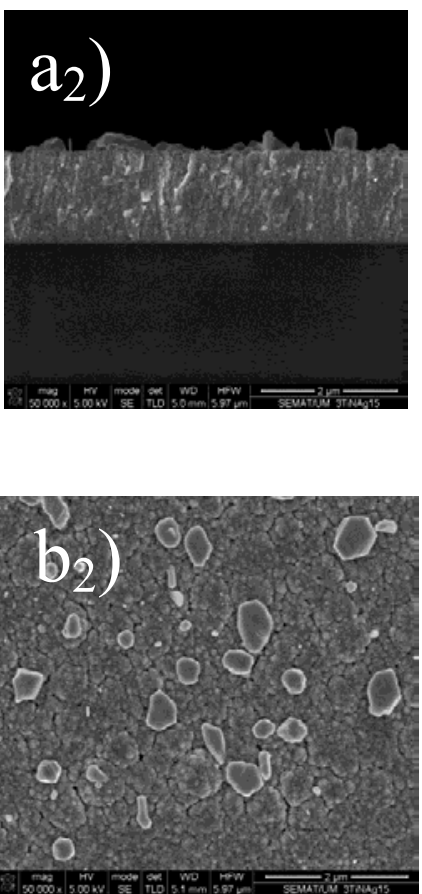

$400^{\circ} \mathrm{C}$
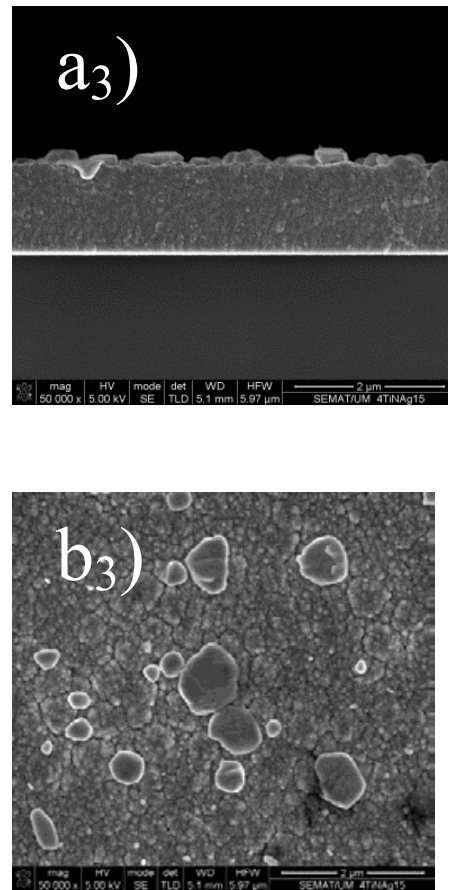

$500^{\circ} \mathrm{C}$
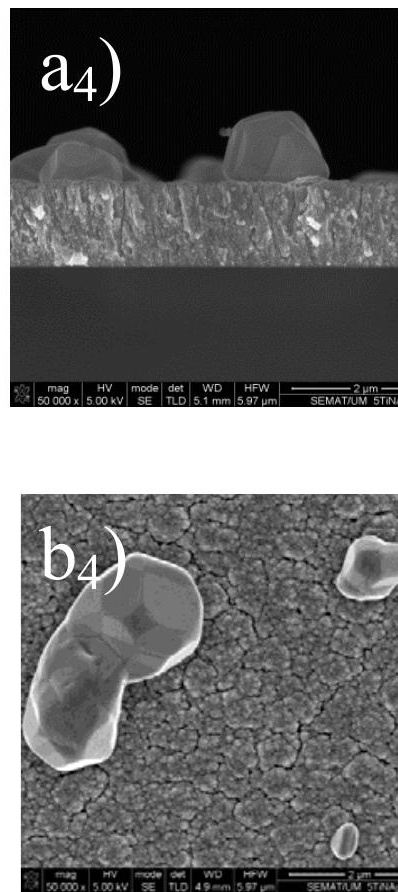
Figure 4

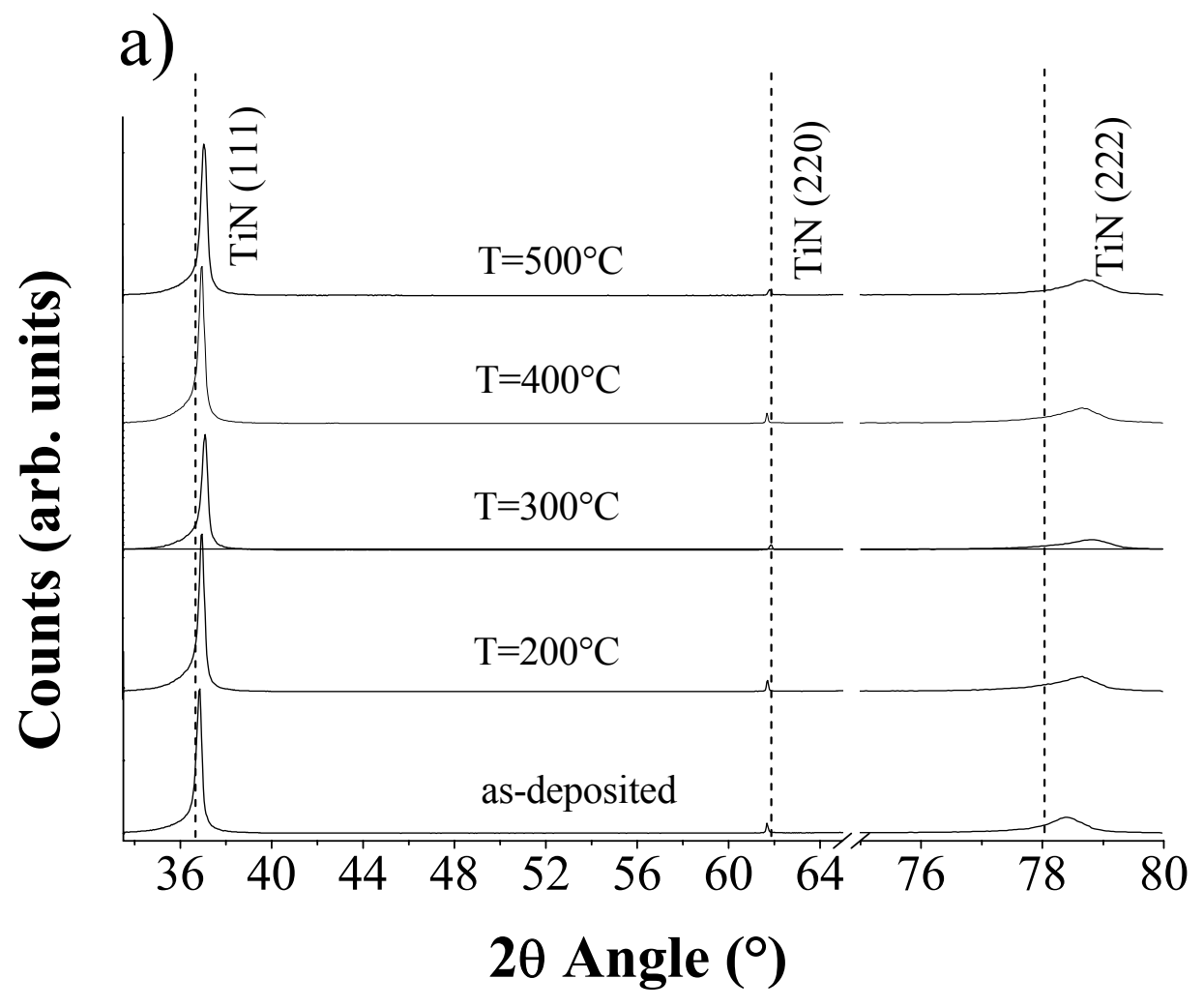




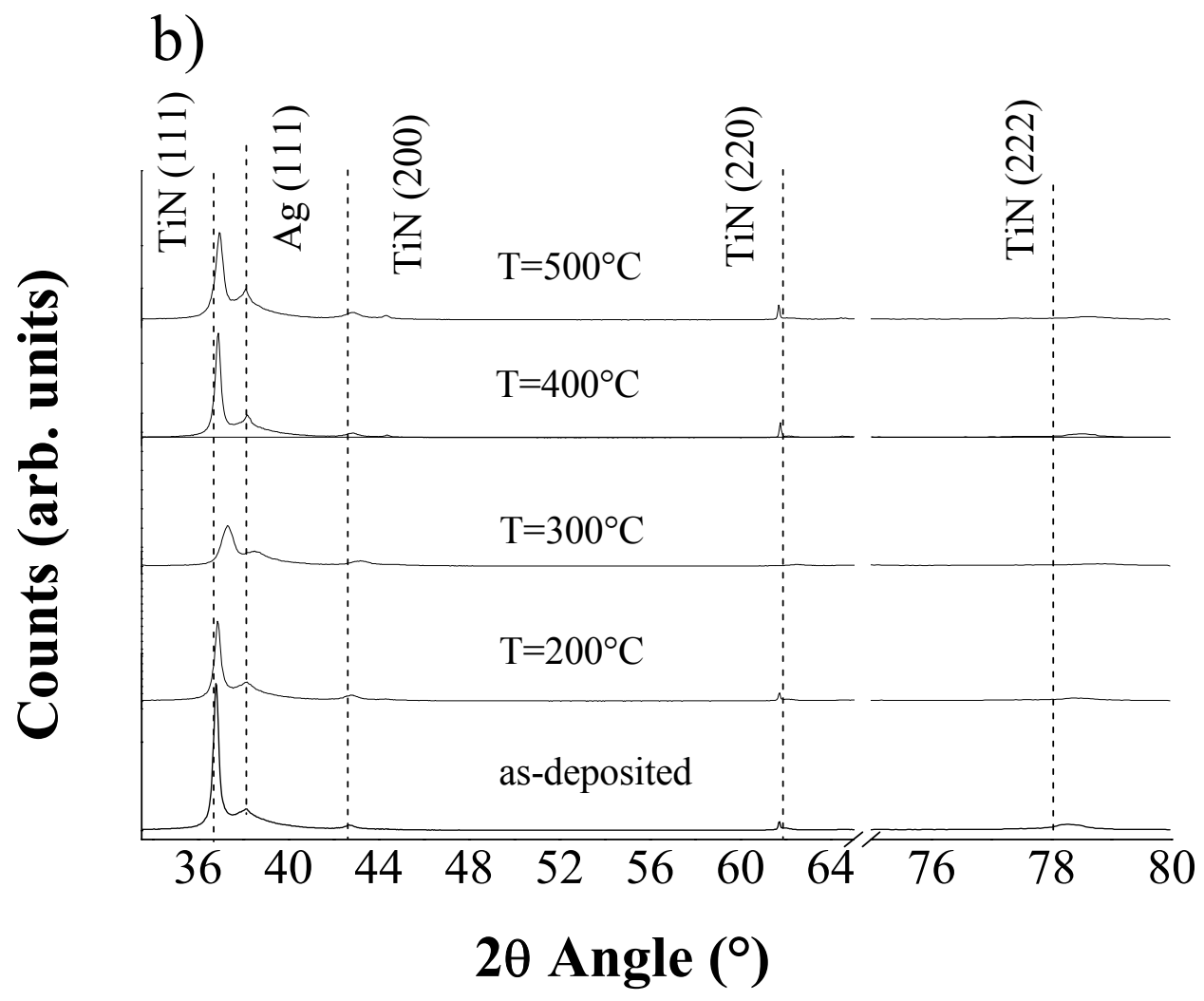




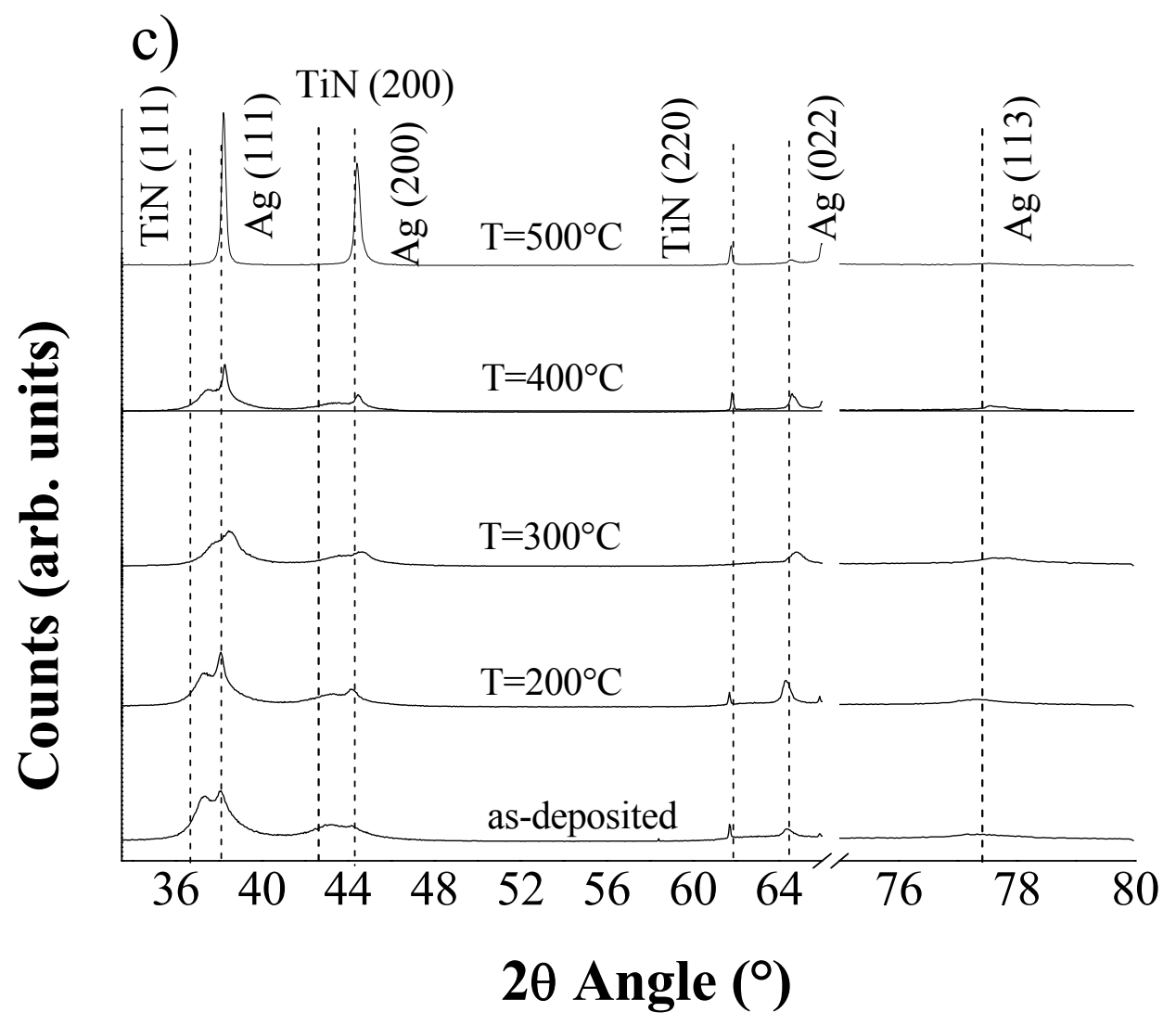


Figure 5

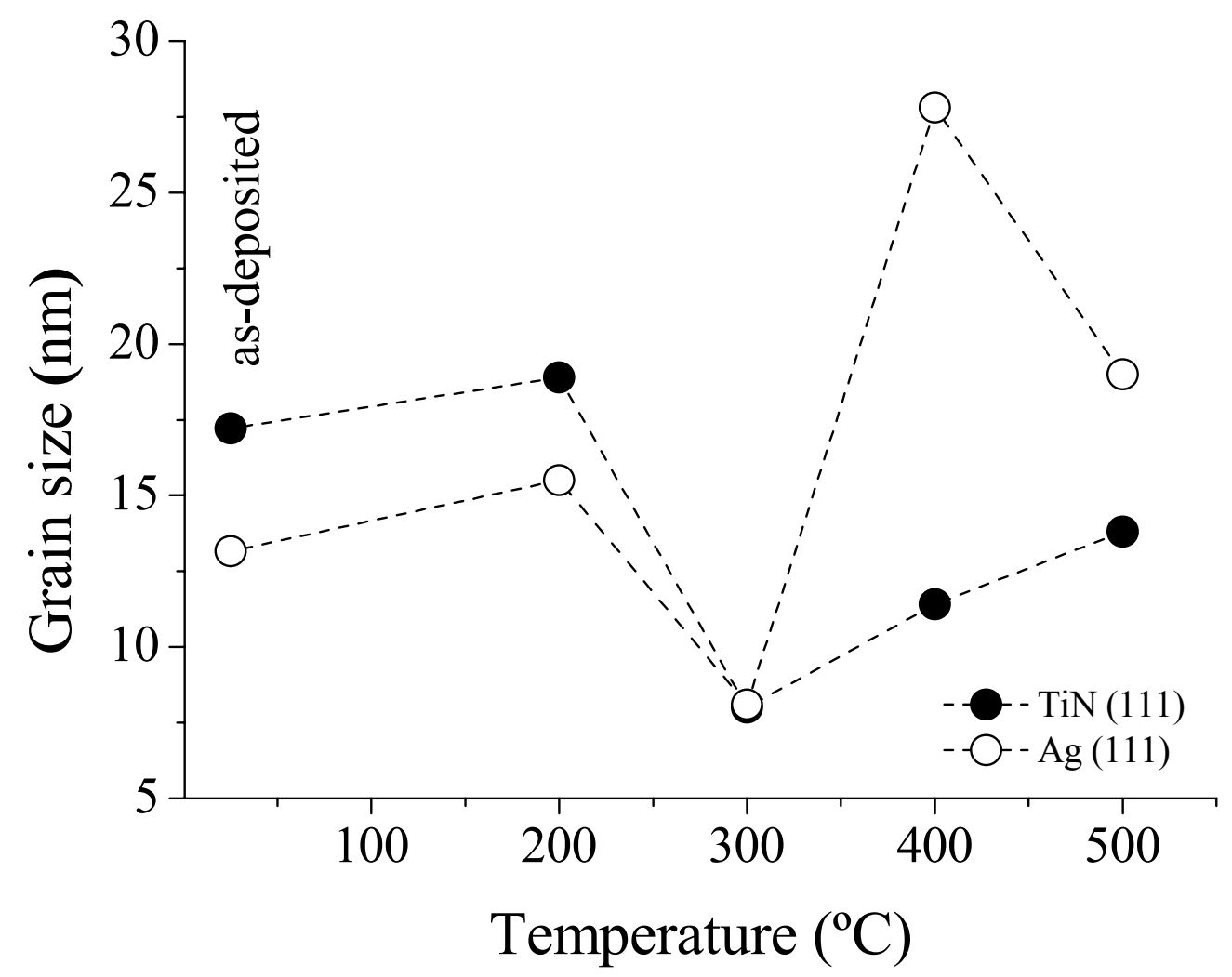


Figure 6

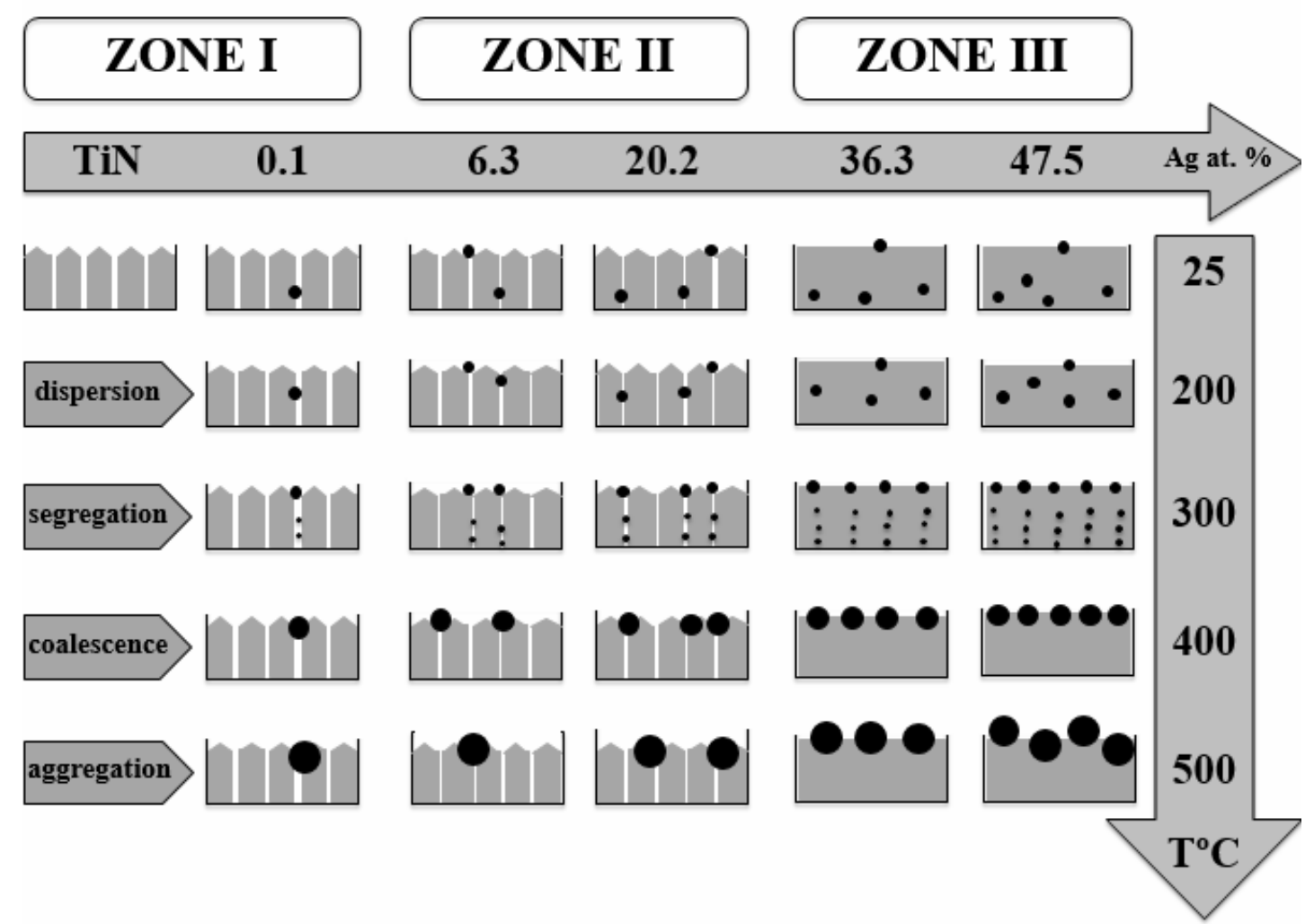

